\title{
Editorial
}

\section{Public health management}

Health care reform remains a key feature of health systems globally but in many countries the currency used to describe developments is changing. Whereas the reform agenda in the 1980s and early 1990 s was dominated by issues arising from the funding, organisation, and management of health care services-largely concerns to do with means rather than ends - the issues that are now high on the reform agenda have more to do with ends-with the effectiveness of health care and its contribution to improved health status. There are also moves to focus more broadly on health rather than health care with health care systems contributing to this agenda though not necessarily as the dominant partner.

There are many reasons for the shift in emphasis and in some respects the agenda is not a new one. Many countries have signed up at a rhetorical or symbolic level to the principles of the WHO's Health for All and Ottowa Charter though few have made significant progress in realising their aims. Countries like the UK have also produced national health strategies although, again, for the most part these have been more impressive for what they have promised than for what has been delivered.

If there is a difference this time it lies in an apparent conversion among policy makers and a commitment on the part of a number of governments to consider the structural determinants of health and to adopt a whole systems approach to tackling these through whole systems thinking and broad based partnerships. Countries like New Zealand, the UK, and others with recently elected reforming governments are committed to finding a third way between outmoded top-down command and control structures on the one hand and inappropriate market oriented systems based on competitive principles on the other.

While a new health policy agenda may be taking shape in various countries, there remain important concerns about the capacity and capability to ensure its implementation. The public health function is central to effective implementation but in many countries suffers from being underdeveloped, dominated by public health medicine, diverted by managerial agendas that have more to do with the efficient running of health care services than with the health of populations, or some combination of these.

With contemporary health systems facing major public health challenges, a false dichotomy has emerged between public health specialists (whether medically qualified or not) and health services management. While public health practitioners have traditionally looked outwards towards society and the health needs of the population, health service managers have tended to focus inwards on the organisation and to become captured by the pressures, and seemingly insatiable demands, of the acute hospital sector. The upshot is a group of managers and a group of public health specialists who do not appear to share the same objectives and who may even work at cross purposes. ${ }^{1}$

The concept of public health management seeks to foster a shared understanding of these various pressures on managers and public health practitioners. If resources are to be used most effectively, then the complex relationships between public health and primary, secondary, and tertiary care need to be better recognised and understood. This is especially so at a time when the boundaries between these sectors are shifting dramatically. The focus of public health management is concerned with "mobilising society's resources, including the specific resources of the health service sector, to improve the health of populations". ${ }^{2}$

If health care reform is about improving the health of a defined population then the principal concern of managers should not be with the health of the institution but with what Evans terms "managerial epidemiology", by which he means "the effective management of resources to maintain and promote the health of populations". ${ }^{3}$

Public health management therefore requires managers who understand the importance of population-based approaches to health and public health specialists who are not mere purveyors of knowledge. They are also change agents and must become skilled in managing change, and in building coalitions of support for change both within the health care sector and across and into other sectors that have a significant impact on health.

Public health management is not exclusively concerned with the analysis of the health needs of the population, health promotion and prevention. It must concern itself with the management of all resources provided from public funds intended to improve the health of populations, including acute care, which has a major contribution to make to secondary prevention.

The power and strength of public health management lie in its origins, namely, the twin traditions of public health and health services management respectively. It endeavours to link knowledge and action because at the heart of public health management is a commitment to changing policy and practice. As the Chief Medical Officer in England, Sir Kenneth Calman, has put it: "The practical implications of public health are an art and require special skills in themselves. Skills need emphasising and include both management and political skills in the communication of ideas and complex public health issues".4

Public health management offers both public health practitioners and health service managers a reminder of the business they are in and a way forward in which the particular skills of both groups are valued and more effectively harnessed. Too often, managers are regarded as "doers" while public health specialists are criticised for dreaming up unworkable schemes and then commenting on how difficult it all is or why lack of progress is the fault of others, usually managers. Public health managerment provides for a synthesis of these different perspectives to ensure that knowledge and action are linked.

As governments in a growing number of countries move to tackle health inequalities and social exclusion strengthening the public health function becomes critical if effective implementation is to occur. With the appointment in England of the first ever Minister for Public Health in May 1997, it is clear that the government's public health strategy cannot be delivered without a robust public health function embracing not just traditional public health professionals but also those with a public health orientation 
in local government, voluntary bodies, academic centres, and elsewhere. ${ }^{5}$

There are encouraging signs that the concept of public health management has moved beyond the realm of academic discourse and is being taken seriously at high levels. For instance, the Chief Medical Officer (CMO) in England was asked by health ministers to review the public health function to ensure its fitness for purpose in the light of the government's plans to shift the focus of health policy towards health. In his report, the CMO acknowledges the importance of education, training, and organisational development in giving all professionals, including managers across a variety of agencies, a basic understanding of public health. In this way their role in furthering health improvement goals would be strengthened.

Developments like those in hand in Britain to put health at the top of the health policy agenda and to ensure that the requisite capacities and capabilities are in place are of considerable relevance to other countries confronting similar public policy problems and agendas. Doubtless, too, Britain can learn from the experience of others, notably Finland, Norway, and Canada, where public health has been a key policy driver at various times.
Organisations like WHO and the World Bank, as well as various health related associations within Europe, are well placed to champion the cause of public health management. A window of opportunity is opening in many countries and it would be a tragedy if public health failed to take full advantage of the prospect of a paradigm shift in health policy that could parallel the gains achieved by the public health movement in many countries over 150 years ago.

1 Hunter DJ. Managing the public health: incorporation or liberation? In: Scally G, ed. Progress in public health. London: Royal Society of Medicine Press, 1997:5-20.

2 Alderslade R, Hunter DJ. Forward march. Health Service fournal 1992;102: 22-3.

3 Evans RG. Healthy populations or healthy institutions: the dilemma of health care management. The fournal of Health Administration Education 1995;13:453-72.

4 Calman K. The scientific basis of public health. Address to the Annual Conference of the Faculty of Public Health Medicine, 1993, Glasgow.

5 Department of Health. Chief Medical Officer's project to strengthen the public health function in England: a report of emerging findings. London: Department of Health, 1998 .

DAVID J HUNTER Nuffield Institute for Health, University of Leeds 